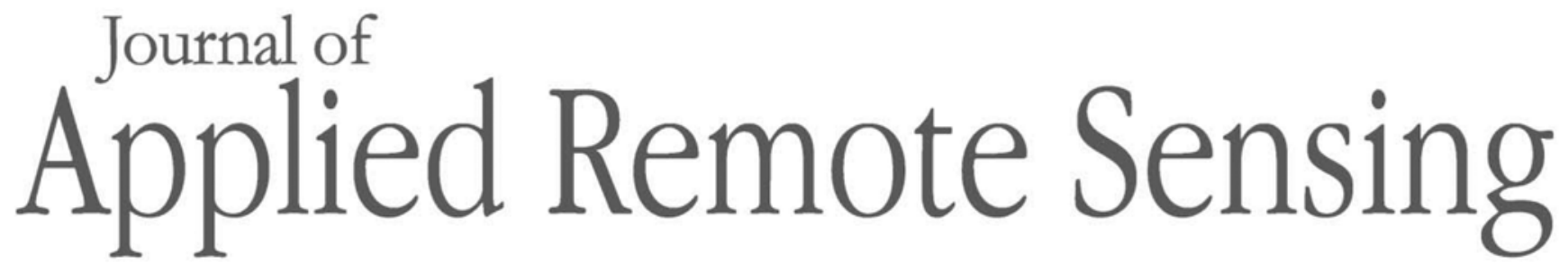

RemoteSensing.SPIEDigitalLibrary.org

\title{
Directional and angular effects on the spectral reflectance of waters with variable amounts of total suspended solids
}

Fábio M. Breunig

Waterloo Pereira Filho

Lênio S. Galvão

Edison Alberti

Joceli Gross 


\title{
Directional and angular effects on the spectral reflectance of waters with variable amounts of total suspended solids
}

\author{
Fábio M. Breunig, ${ }^{\mathrm{a}, \mathrm{b}}$ 网 Waterloo Pereira Filho, ${ }^{\mathrm{c}}$ Lênio S. Galvão, ${ }^{\mathrm{b}}$ \\ Edison Alberti, ${ }^{c}$ and Joceli Gross ${ }^{\mathrm{c}}$ \\ ${ }^{a}$ Universidade Federal de Santa Maria, UFSM campus de Frederico Westphalen, \\ Departamento de Engenharia Florestal, Frederico Westphalen, Brazil \\ ${ }^{\mathrm{b}}$ Universidade Federal de Santa Maria, Centro de Ciências Naturais e Exatas, \\ Departamento de Geociências, Santa Maria, Brazil \\ 'Instituto Nacional de Pesquisas Espaciais, Divisão de Sensoriamento Remoto, \\ São José dos Campos, Brazil
}

\begin{abstract}
Viewing geometry is one of the most important factors to consider when water bodies are observed from satellite sensors with large field of view. We examine the directional and angular effects on the reflectance of waters with different concentrations of total suspended solids (TSSs). In the laboratory, we measure the reflectance in five view zenith angles (VZAs) and eight view azimuth angles (VAAs) for optically shallow waters having four concentrations of TSSs. Seven empirical models to estimate TSSs based only on the reflectance of the red band $(\sim 660 \mathrm{~nm})$ are evaluated. In addition, we analyze Moderate Resolution Imaging Spectroradiometer (MODIS)/Terra reflectance measured in 13 consecutive satellite overpasses. The results show that the reflectance of the inland-like water is affected by data acquisition geometry. The best wavelength to estimate TSS is $625 \mathrm{~nm}$ for most VZAs and VAAs. The lowest correlations between reflectance and TSS are observed at extreme viewing with the anisotropy decreasing with increasing concentrations of TSSs. Directional and angular effects are also observed for MODIS (acquired and simulated data) with TSS underestimates observed close to the orthogonal plane for all VZAs, and TSS overestimates observed in the principal scattering plane in the forward scattering direction. More anisotropic waters are observed for VZA greater than \pm 30 deg. Results highlight the need for correcting MODIS data for bidirectional effects in inland water studies. ( 12019 Society of Photo-Optical Instrumentation Engineers (SPIE) [DOI: 10.11171 [.JRS.13]024524]
\end{abstract}

Keywords: remote sensing; water; reflectance; moderate resolution imaging spectroradiometer; empirical models; bidirectional reflectance distribution function.

Paper 180978 received Dec. 21, 2018; accepted for publication May 20, 2019; published online Jun. 10, 2019.

\section{Introduction}

Optical remote sensing has been widely used to characterize the quality and dynamics of inland waters in different regions of the world $\mathbb{Q}^{-}$Depending on the size of the water bodies, large fieldof-view (FOV) sensors, such as the Moderate Resolution Imaging Spectroradiometer (MODIS), provide the necessary data to evaluate changes in optically significant constituents (OSCs) over time through the increase in the revisit time of the scene. On the other hand, the monitoring of small water bodies requires the use of better spatial resolution instruments than MODIS, such as the Multispectral Instrument/Sentinel-2 and Operational Land Imager/Landsat-8.

For sensors with spatial resolution better than $10 \mathrm{~m}$, the frequency of image acquisition can be improved using satellite constellations (e.g., RapidEye) and the pointing capability of their multispectral sensors. Thus, in both cases (MODIS or RapidEye), the data are generally acquired with different view zenith angles (VZAs), view directions (backscattering and forward scattering) and solar zenith angles (SZAs). SZAs may change seasonally at middle latitudes with differences over

*Address all correspondence to Fábio M. Breunig, E-mail: breunig@ufsmbi

$1931-3195 / 2019 / \$ 25.00$ (C) 2019 SPIE 
time $>20 \mathrm{deg}$. Therefore, in time series analysis of off-nadir data acquired over waters, it is important to consider the influence of view-illumination geometry on the seasonal behavior of OSCs and on their estimates from analytical, semi-analytical, and empirical modeling. 9 .

Despite the potential effects of view-illumination geometry on the spectral reflectance of waters and the correction alternatives,, 1 little attention has been given to the directional and angular effects on OSC estimates for inland waters and satellite-based estimates. 12 14 Apparent optical properties of natural waters depend both on the medium and on the directional (geometric) structure of the radiance distribution. They display sufficient regular features and stability to be useful descriptors of a water body. ${ }^{15}$ Even knowing that reflectance is measured in the conical or hemispherical domain, 1 the bidirectional reflectance 10 presents a dependence on the view-illumination geometry and OSCs. Only the volume reflection carries information on the water quality. In addition, the surface- and bottom (background)-reflected radiation needs to be removed from the upwelling radiance. 1

Among the studied OSCs in inland waters, the total suspended solids (TSS) can be a proxy to evaluate the whole ecosystem conditions. process of sediment transportation from terrestrial to aquatic ecosystems, including erosion and deposition. can rapidly change the aquatic environment. The transportation of sediments into the reservoirs reduces their useful life and efficiency, affecting the biological communities.

Intensive fieldwork and subsequent laboratory analysis are used for precise measurements of TSSs, but this approach is spatially limited and time-consuming. An alternative is to use these measurements in conjunction with satellite images to develop empirical models, or inversion of radiative transfer models, to estimate the TSSs on a per-pixel basis, covering much larger areas. 6 Several empirical relationships between field/laboratory TSS measurements and reflectance have

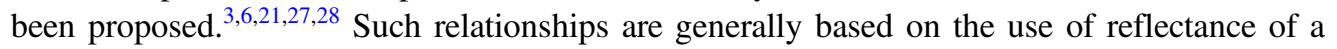
single band, spectral indices, and band ratio with multiple regression models. Using singleband approaches, TSS can be overestimated or underestimated if the input pixel reflectance is affected by view-illumination geometry when large FOV sensors or instruments with pointing capability are used in the data analysis. ${ }^{2}$ However, the effects of the geometry of data acquisition on the empirical modeling of TSSs are still poorly understood. Conversely, radiative transfer models, 3 such as hydrolight 33 can address this problem by simulating the spectral radiance distribution as a function of the view direction, water depth, and wavelength. 1 On the other hand, such models usually require several parameters and highly qualified users, which makes empirical models an attractive alternative to study such effects on TSS determination.

In this study, we performed a laboratory experiment to evaluate viewing geometry effects on the spectral reflectance of inland-like waters having different concentrations of TSSs. We investigated such effects on TSS estimates, derived from seven empirical models proposed in the literature by simulating the spectral resolution of MODIS from spectrometer data collected over a water tank. Finally, the spectral reflectance of waters from a reservoir with high concentrations of TSS was inspected for consistency using MODIS data acquired over consecutive overpasses with different viewing geometries.

\section{Materials and Methods}

\subsection{Experiment Design and Measurements}

The design of this viewing geometry study for spectral measurements of waters under different TSS concentrations comprised 99 different combinations of data acquisition parameters (Fig. (1). We evaluated differences in spectral reflectance as a function of viewing geometry [five VZAs and eight view azimuth angles (VAAs)] and TSS concentrations [Fig. [1(a)]. This analysis was based on data acquired on the principal plane (azimuth zero) and with VAA of $0 \mathrm{deg}, 45 \mathrm{deg}$, $90 \mathrm{deg}$, and $135 \mathrm{deg}$. Five VZAs were considered: $0 \mathrm{deg}$ (nadir), $15 \mathrm{deg}, 30 \mathrm{deg}, 45 \mathrm{deg}$, and $60 \mathrm{deg}$ [Figs. 1(b)] and 1(c)]. The principal and orthogonal scattering planes are indicated in Fig. 1(a) to illustrate the backscattering and forward scattering directions. Photographs of the water tank with different TSS concentrations were taken as ancillary data [Fig. [1(d)]. 


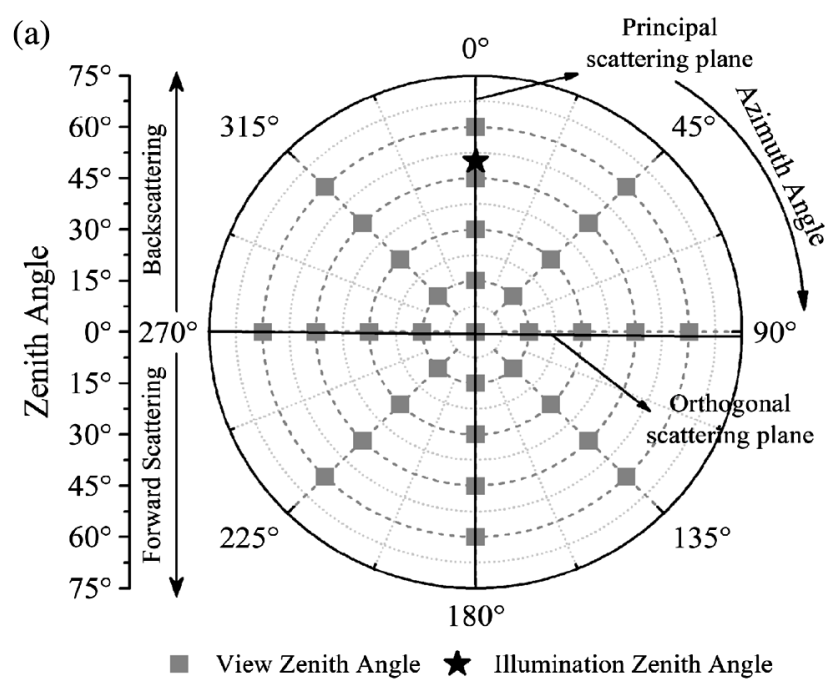

(b)

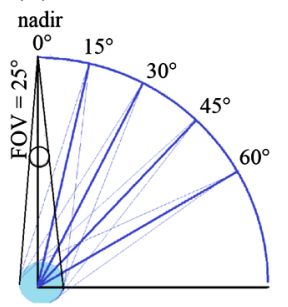

(c)

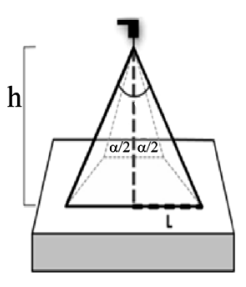

(d)

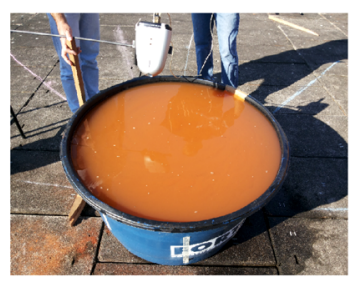

Fig. 1 The experiment design illustrating the (a) simulated view-illumination geometries for eight azimuth angles, (b) data acquisition at 15-deg intervals for VZA ranging from nadir to 60 deg, (c) nadir projected FOV of the handheld spectrometer, and (d) the water tank used in the study. At nadir, the distance from the sensor to water was $30 \mathrm{~cm}$. $L$ refers to the FOV radius and $h$ to the height above water surface.

The outdoor experiment to better represent diffuse skylight was performed in August 27, 2015 , close to the noon and in a minor time interval. The objective was to reduce SZA variations and to better observe the anisotropy of the waters with different TSS concentrations in the tank. The SZA is one of the main drivers of surface reflection. $\$$ The Sun was used as the source of illumination to obtain spectral measurements. As indicated in Fig. \&, the variation in SZA between the beginning and end of the measurements was $5.98 \mathrm{deg}$. In the beginning of the experiment, the VAA was adjusted to zero (principal plane) and shifted by 45-deg steps.

The experiment was carried out in the South Regional Centre (CRS) of the Brazilian National Institute for Space Research (INPE) in the Santa Maria municipality (S 29 $41^{\prime} 47^{\prime \prime} / \mathrm{W} \mathrm{53^{ \circ }}$ 43'33'). A black-painted water tank of 3101 was used. Four concentrations of TSS were simulated: clear water without TSS; low ( $<5.00 \mathrm{mg} / \mathrm{L})$, intermediate $(5.00$ to $30.00 \mathrm{mg} / \mathrm{L})$, and high ( $>30.00 \mathrm{mg} / \mathrm{L}$ ) TSS concentrations. Just after each predissolved TSS addition, the water tank was mixed during $1 \mathrm{~min}$ to avoid settling. It is important to note that sand fraction settles quite quickly rather than clay and silt. However, larger sand particles tend to contribute relatively little to the measured light scattering than the much more numerous clay and silt particles. The sediment used in the experiment was composed of $48 \%$ of clay, $30 \%$ of silt, and $22 \%$ of sand. It is similar in composition to Rhodic Acrustox (Latossolo Vermelho in the Brazilian system of soil classification), a common soil type in southeastern Brazil. After adding the solids into the tank, we determined precisely the TSS using $600 \mathrm{~mL}$ of water and preweighted cellulose filters of $45 \mu \mathrm{m}$ of porosity and $47 \mathrm{~mm}$ of diameter. The TSS was measured by the difference between the initial and final weights of the filters, as a function of the water volume filtered in milligram/liter. The TSS was calculated by subtracting the postweight from the preweight dry filter for each water sample. The water turbidity was measured using nephelometric turbidity unit (NTU) to validate the TSS measurements and avoid errors (Table 11). 


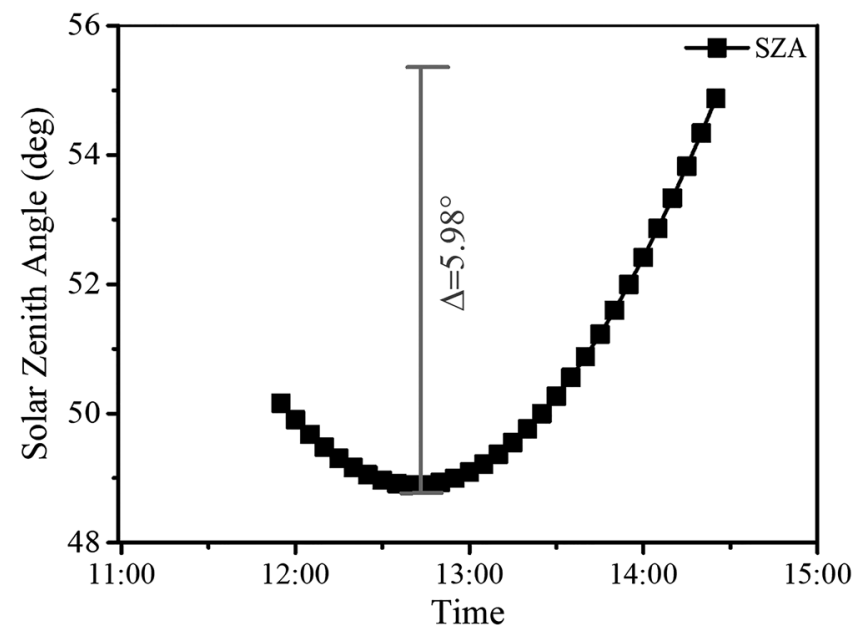

Fig. 2 Variation in SZA during the water tank experiment. The local time and duration of the experiment are indicated by symbols. $\Delta$ refers to SZA range during the experiment.

Table 1 Measured TSS (mg/L) and water turbidity (NTU) in different steps of sediment concentration.

\begin{tabular}{lc}
\hline \hline TSS concentration $(\mathrm{mg} / \mathrm{L})$ & Water turbidity (NTU) \\
\hline 4.00 & 0.00 \\
17.33 & 10.70 \\
126.00 & 114.00 \\
\hline \hline
\end{tabular}

For reflectance data acquisition (actually hemispherical-conical reflectance factor), the FieldSpec handheld instrument was used ${ }^{3}$ This spectrometer operated in the 400- to 900$\mathrm{nm}$ spectral range at $1-\mathrm{nm}$ interval (resampled). The radiance measurements were calibrated using white Spectralon ${ }^{3}$ The spectrometer was set up to acquire 10 measurements on each view-illumination geometry. To reduce noise, we used the average of these measurements. At extreme viewing, a shift in the instrument was necessary to avoid edge effects of the tank. In the absence of a fore optics accessory to reduce the 25-deg FOV of the spectrometer, which could also affect the quality of the data collected over water, we used the conventional fiber optic cable to measure radiance (25-deg FOV). In practice, this strategy may exaggerate some of the bidirectional reflectance distribution function (BRDF) effects.

\subsection{Data Analysis}

Pearson's correlation coefficients for the relationships between the spectral reflectance and TSS concentration were obtained in the 400- to 900-nm range. For this purpose, we used spectral measurements from the 12 simulations for each view geometry, encompassing the four TSS ranges of concentration.

After identifying the optimal wavelengths and the best geometry of data acquisition to estimate the TSSs, we studied directional and angular effects on the spectral response by normalizing the data to the nadir spectral response. We calculated the anisotropy factor (ANIF) using Eq. (11).

$$
\mathrm{ANIF}=\frac{\text { Reflectance }_{\text {off nadir }}}{\text { Reflectance }_{\approx \text { nadir }}} .
$$

In a subsequent analysis, despite the quite different measurement scenarios of MODIS and field spectrometer, we simulated the spectral resolution of the MODIS/Terra instrument using its 
Table 2 Seven empirical models proposed in the literature to estimate TSS in different inland waters of the world (reservoir, bays, costal, and ocean) using MODIS data from the red band 1 ( $x$ in the equations).

\begin{tabular}{|c|c|}
\hline Model & Reference \\
\hline$y=-1.91+1140.25 * x$ & Miller and McKee \\
\hline$y=828.57 * x-20.68$ & Park and Latrubesse \\
\hline$y=27.05 * e^{7.83 * x}$ & Park and Latrubesse \\
\hline$y=36.73 * e^{6.17 * x}$ & Park and Latrubesse \\
\hline$y=649.99 * x+3.42$ & Park and Latrubesse \\
\hline$y=602.63 * x+3.1481$ & Rodríguez-Guzmán and Gilbes-Santaella \\
\hline$y=-5.60 *\left[1-e^{(-0.10 * x)}\right]$ & Breunig et al. \\
\hline
\end{tabular}

Note: The scale factors of MODIS reflectance data are different for each model and are adjusted in the current study.

filter functions. The spectral resampled data were normalized to nadir [Eq. (11)] and plotted as a function of the VZA and VAA. Because MODIS has been widely used to estimate TSSs, such simulated data were used to complement the analysis, avoiding direct comparison across laboratory (centimeters) and orbital (meters) scales. In reality, pixel size ranges with VZA during MODIS data acquisition. Because of the bowtie effect, MODIS ground-projected instantaneous field of view (GIFOV) reaches $\sim 2.0$ times the nadir resolution pixel size in the track direction and 4.8 times in the scan end direction. ${ }^{3}$ Therefore, for a nominal pixel of $250 \mathrm{~m}$, the GIFOV can range between 344 and $835 \mathrm{~m}$ across track and between 292 and $523 \mathrm{~m}$ along track when the VZA ranges from $0 \mathrm{deg}$ (nadir view) to $55 \mathrm{deg}$. 8 四

Some studies showed that single-band models are effective to retrieve TSS 四 To illustrate the impacts of the directional and angular effects on TSS estimates derived from available empirical models, we tested six empirical models (not site calibrated) reported in the literature that used the MODIS red band 1 (620 to $670 \mathrm{~nm}$ ) (Table [). The calculations were performed for the different view geometries. In addition, we used a local exponential model proposed to estimate TSSs in subtropical reservoirs from South Brazil (Table Z). This empirical model was created using TSS measured in 12 field campaigns and MODIS MCD43A4 (Nadir BRDF-Adjusted Reflectance 16-Day L3 Global $500 \mathrm{~m}$ ) data of the red band 1 to compensate for bidirectional effects $\$$

Finally, the MODIS surface reflectance of the red band (product MOD09GA Surface Reflectance Daily L2G Global $1 \mathrm{~km}$ and $500 \mathrm{~m}$ ) was used to study the effects of view angle and view direction in the transition from laboratory- to orbital-level of data acquisition. For this purpose, we used 13 images acquired in consecutive days and under different view observations and directions (backscattering and forward scattering) over the Passo Real reservoir, located in South Brazil. The MODIS product was preprocessed using the MRT algorithm, in order to convert the sinusoidal projection to planar UTM coordinates.

\section{Results and Discussion}

\subsection{Viewing Geometry Effects and Total Suspended Solids Concentration}

The spectral response of the inland-like water of the tank was affected by view angle and view direction. For instance, when we examined the spectra in four VAAs ( $0 \mathrm{deg}, 45 \mathrm{deg}$, $90 \mathrm{deg}$, and $135 \mathrm{deg}$ ) and five VZAs (nadir, $15 \mathrm{deg}, 30 \mathrm{deg}, 45 \mathrm{deg}$, and $60 \mathrm{deg}$ ), we observed an increase in the blue reflectance for clear water $(\mathrm{TSS}=0 \mathrm{mg} / \mathrm{L})$ from nadir $(\mathrm{VZA}=0 \mathrm{deg}$ ) to extreme viewing $(\mathrm{VZA}=60 \mathrm{deg}$ ), especially in the principal plane (VAA $=0 \mathrm{deg}$ ) (Fig. 3). At $60 \mathrm{deg}$, the sky reflection should be considered. Such variation was attributed to water 
fluctuations due to low wind conditions (not measured). This effect was also observed at increasing TSS concentrations, which produced an overall reflectance increase, especially in the red interval $(600$ to $700 \mathrm{~nm})$ and at VAA of $135 \mathrm{deg}$. For the highest TSS concentration $(60 \mathrm{mg} / \mathrm{L})$ [Fig. 3(d)], the backscattering direction (VAA of 0 deg and $45 \mathrm{deg}$ ) presented lower reflectance than that observed in the forward scattering direction (VAA of $90 \mathrm{deg}$ and $135 \mathrm{deg}$ ).

Several studies to estimate TSSs empirically in inland waters used regression analysis. intervals are generally indicated in the literature as adequate to estimate TSSs. ${ }^{3-4}$ In our study, by linearly correlating the spectral reflectance of the water having four different TSS concentrations, we verified that the highest correlation coefficients were obtained in the red for wavelengths $>600 \mathrm{~nm}$, including the transition into the NIR, for most geometries of data acquisition [Figs. 4(a) and 4(b)]. Despite the good correlations for the NIR reflectance for some geometries, the best wavelength to estimate TSSs was $625 \mathrm{~nm}$ for most of the VZAs and VAAs. However, results from Fig. 4(b) indicated that the specular direction (VAA of 180 deg and nearby), which presented low correlation coefficients at extreme viewing, should be avoided to estimate TSSs.

\subsection{Anisotropy of the Spectral Response of Water at $625 \mathrm{~nm}$}

The ANIF at $625 \mathrm{~nm}$ (center of the MODIS red band 1), the wavelength that presented the best correlation results in Fig. 4 , indicated a reduction in directional and angular effects with

(a)
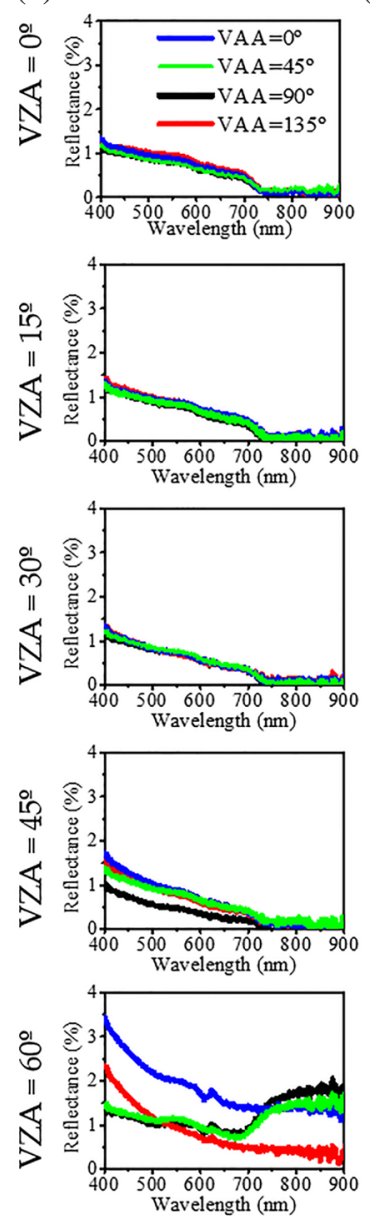

(b)
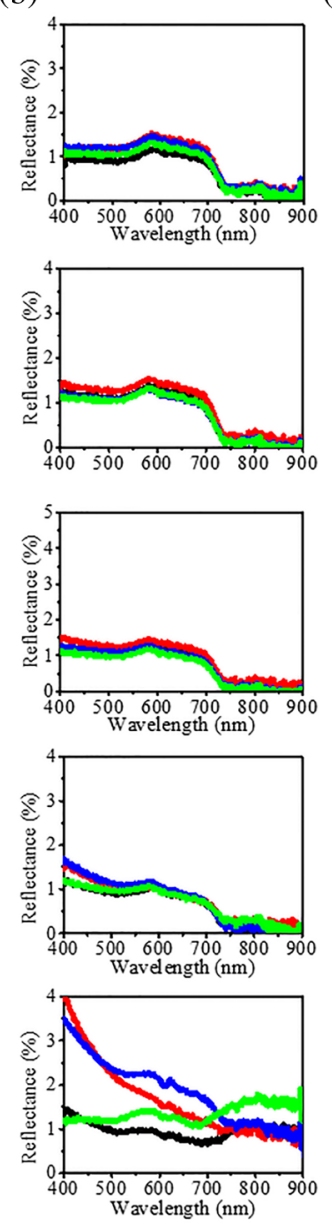

(c)
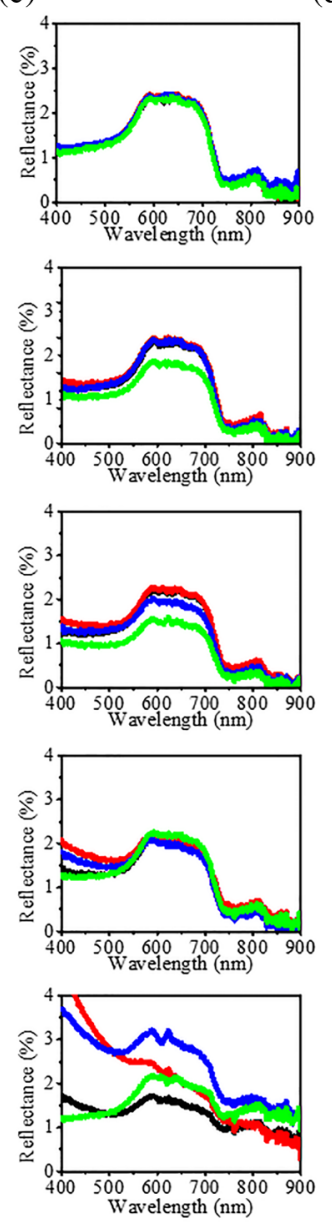

(d)
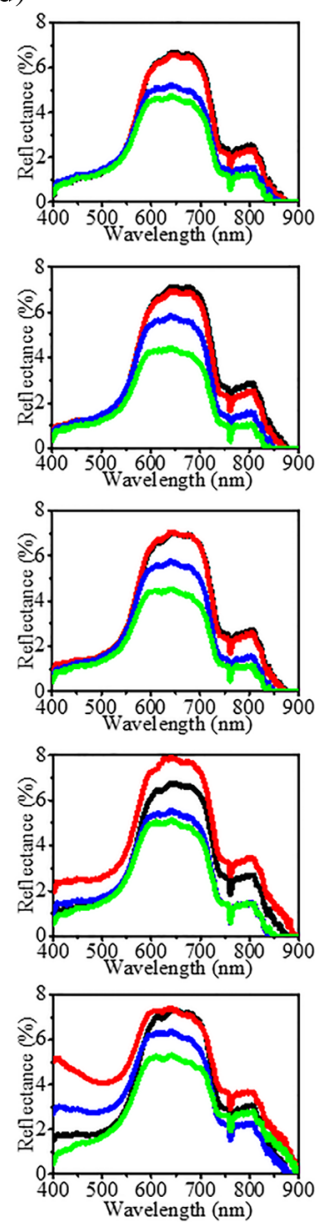

Fig. 3 Variation in spectral reflectance of the experiment with great changes in VZA and VAA for (a) clear water, (b) low (4 mg/L), (c) intermediate $(8.67 \mathrm{mg} / \mathrm{L})$, and (d) high $(60 \mathrm{mg} / \mathrm{L})$ TSS concentrations. Results from the specular direction (VAA $=180 \mathrm{deg})$ are omitted to facilitate graphic representation. 

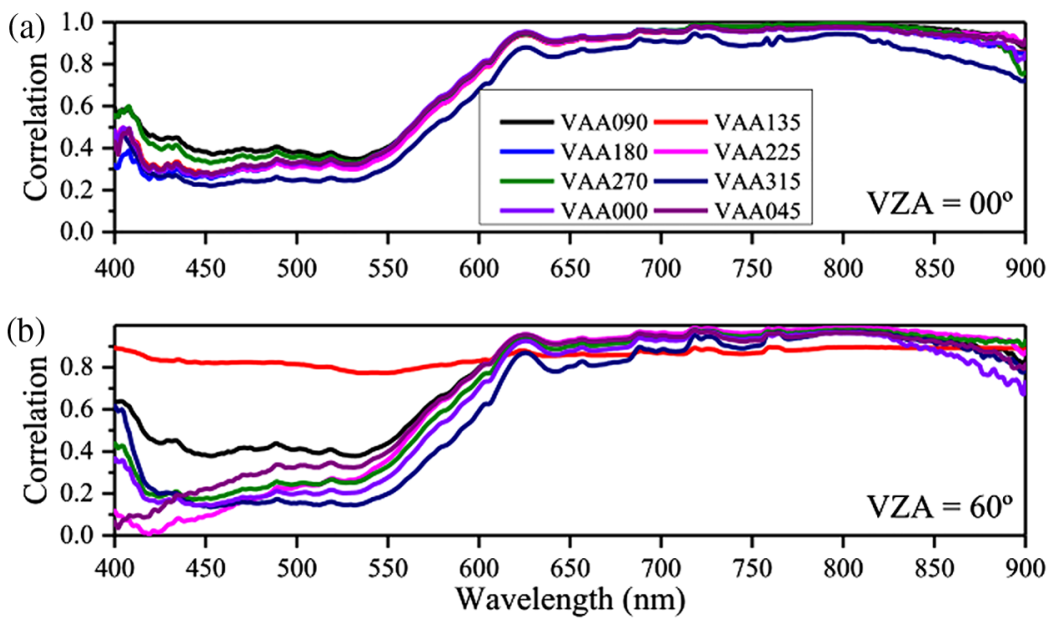

Fig. 4 Variation in Pearson's correlation coefficients $(n=12)$ for the relationship between the spectral reflectance of water and the TSS concentrations, as a function of the VAAs. Results are shown for VZAs of (a) 0 deg (nadir) and (b) 60 deg. In (b), the VAA of 180 deg presents negative correlations up to -0.4 for all wavelengths.

increasing TSS concentrations [Figs. $5(\mathrm{a})-5(\mathrm{~d})]$. Although the sediment was properly mixed, the increase in TSS produced a more heterogeneous water surface ("roughness") and a lower water transparency, reducing the effects of the geometry of data acquisition. Higher TSS concentrations increased the diffuse component of the reflected radiation by the water but decreased the specular component derived from the smooth water surface without TSS.
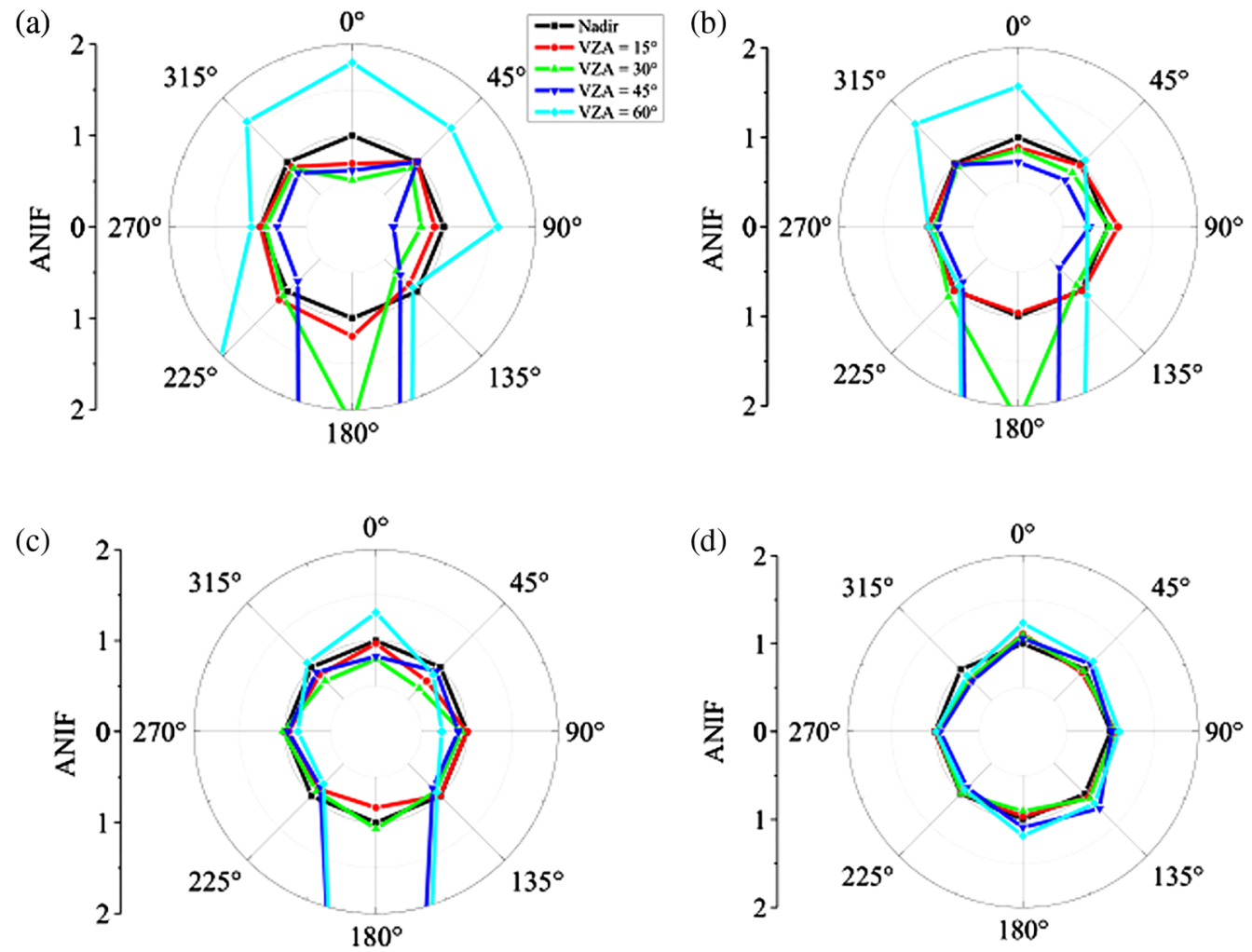

Fig. 5 Polar graphs showing the ANIF at $625 \mathrm{~nm}$, as a function of the VZA (identified by colors) and VAA (degree in the graphs), for clear water (a), and waters having TSS concentrations of (b) $4 \mathrm{mg} / \mathrm{L}$, (c) $8.67 \mathrm{mg} / \mathrm{L}$, and (d) $60 \mathrm{mg} / \mathrm{L}$. Large ANIF values at 45-deg and 60-deg VZA are omitted for a better graphical representation. 


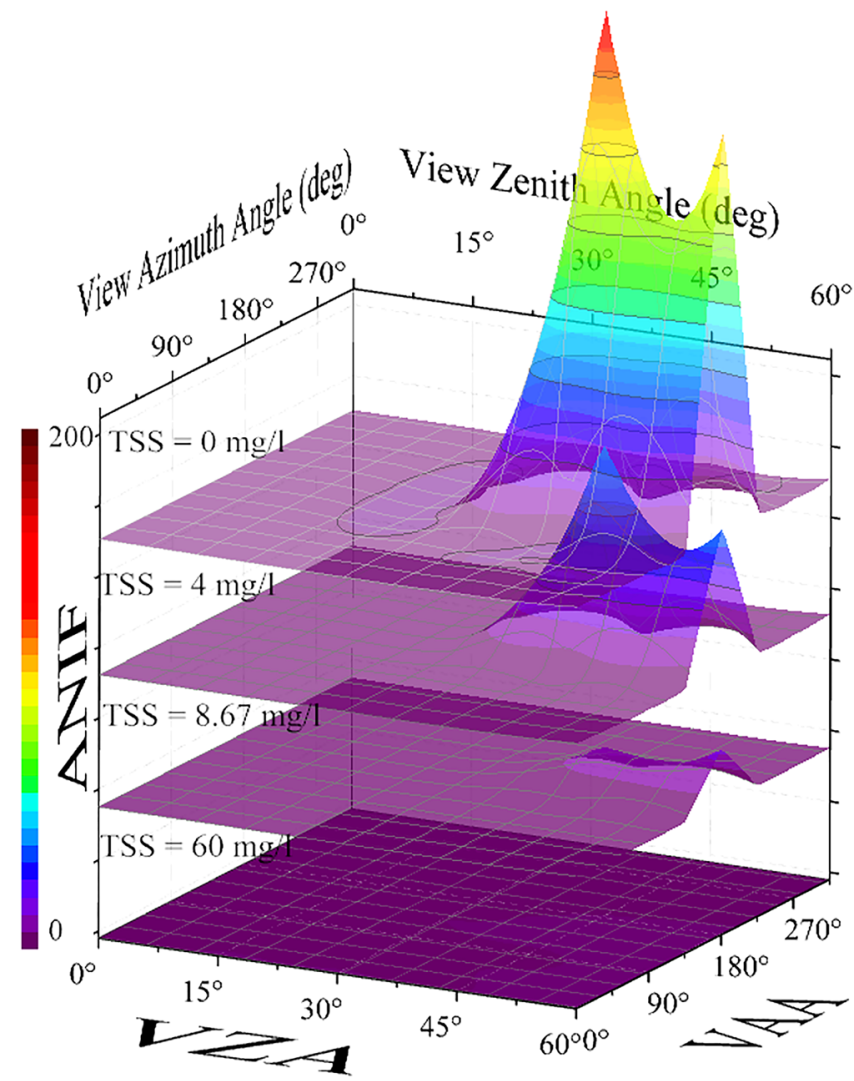

Fig. 6 Variation in the ANIF at $625 \mathrm{~nm}$ as a function of the TSS concentration and viewing geometry for the experiment described in the text. The graphs are stacked to accommodate graphical representation.

In Fig. 5(a), the great reflectance anisotropy of clear water is indicated by nadir-normalized reflectance values $>1$ and by asymmetric contour curves. For any geometry of data acquisition, the ANIF decreased to values close to 1 and the contour curves became more symmetric when the TSS reached values up to $60 \mathrm{mg} / \mathrm{L}$ [Fig. 5(d)]. At large VZAs, the reflectance was higher in the forward scattering direction (specular) than in the backscattering direction. For clear water [Fig. 5(a)], directional effects were stronger at VZA higher than $30 \mathrm{deg}$, especially in the specular direction. At low TSS concentration $(4.00 \mathrm{mg} / \mathrm{L})$, the anisotropy decreased at 30-deg VZA [Fig. 5(b)]. Sequentially, by adding more sediments $(8.67 \mathrm{mg} / \mathrm{L})$ into the tank, the water became more isotropic at 45-deg VZA [Fig. 5(c)] In the last case, when the TSS reached $60 \mathrm{mg} / \mathrm{L}$, even at 60-deg VZA, there was a low dependence of the directional effects [Fig. 5(d)]. Therefore, the increase in overall reflectance (albedo) produced by greater amounts of TSSs, probably enhanced the geometric effects, while the decrease in specular component of the water reduced the directional influence.

Results depicted in Fig. 6 confirmed the reduction in the directional effects on the reflectance anisotropy (ANIF) at $625 \mathrm{~nm}$ with increasing TSS concentrations, as indicated by flat colored surfaces in the lower portion of the figure.

\subsection{Reflectance Anisotropy and Empirical Estimates of Total Suspended Solids}

Directional and angular effects were also observed when we simulated the broadband of the MODIS/Terra instrument (Fig. 7). For MODIS-simulated data, the greatest differences in the blue region were found for 60-deg and 45-deg VZAs and for 0-deg and 135-deg VAAs [Figs. 7(a) and 7(d)], respectively. When the sensor azimuth was closer to the orthogonal 

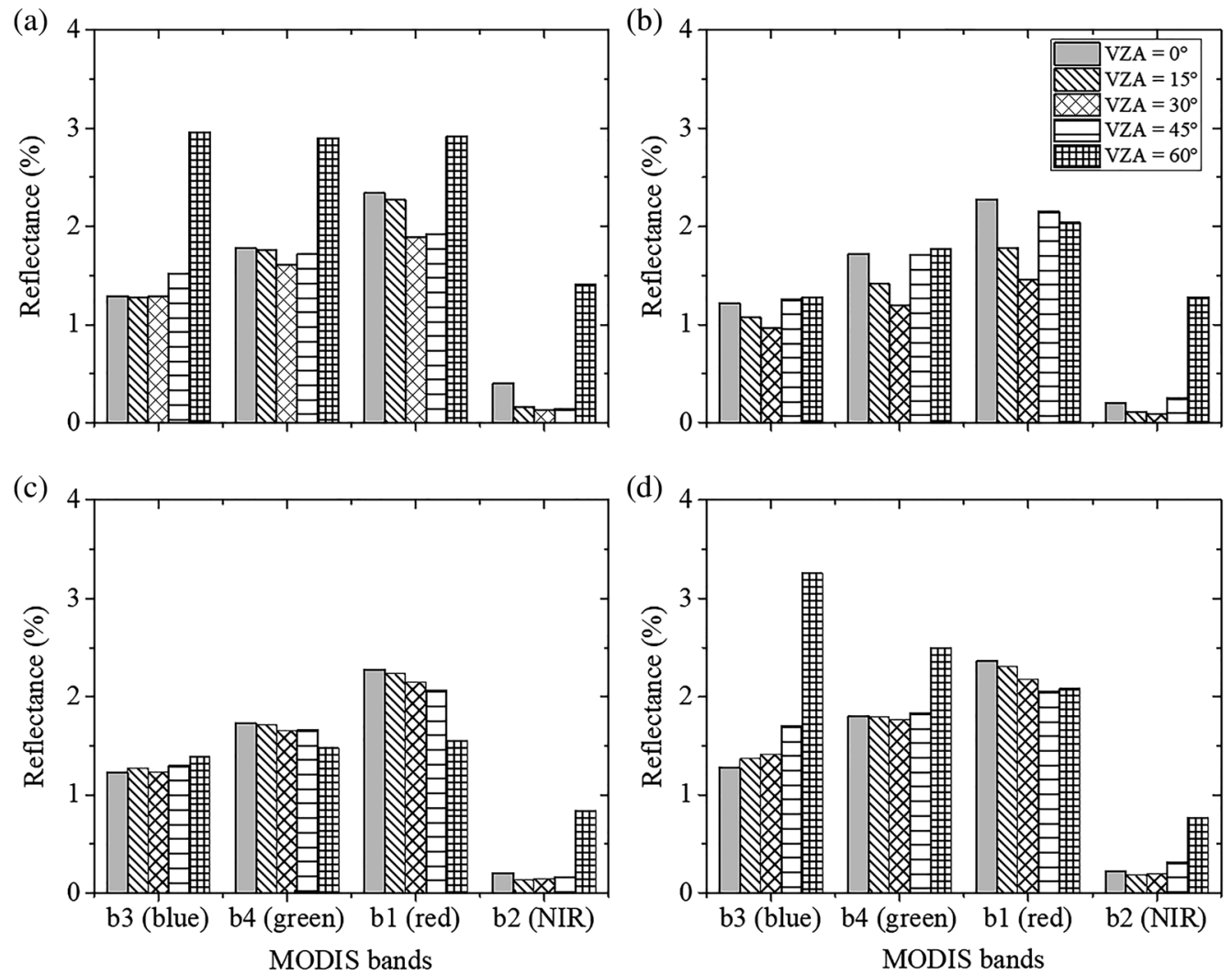

Fig. 7 MODIS-simulated reflectance spectra of waters having TSS concentration of $8.67 \mathrm{mg} / \mathrm{L}$ for different VZAs and VAAs. The VAAs are: (a) 0 deg (principal plane), (b) 45 deg, (c) 90 deg (orthogonal plane), and (d) 135 deg.

plane (VAA of $90 \mathrm{deg}$ ), a lesser degree of variation in spectra shape was observed, except for extreme viewing at 60-deg VZA [Fig. T(c)] .

Several empirical relationships between TSS and red band reflectance have been proposed in the literature. 27286 Our results demonstrated that the directional and angular effects on TSS estimates by these empirical relationships (Table B) presented great differences with the geometry of data acquisition (Fig. 8). To facilitate graphic representation, data from 180-deg VAA at 45-deg and 60-deg VZA due to specular effect were removed (Fig. 8). These estimates were scaled to facilitate visual evaluation of the directional and angular effects. Close to the orthogonal plane (90-deg and 270-deg VAAs), the TSS estimates provided by all models were generally lower for all VZAs (Fig. (8)). However, in the principal scattering plane in the forward scattering direction, overestimates were observed. At high TSS concentration, the forward scattering direction presented higher estimates of TSS than the backscattering direction for both high and low TSS-adjusted models (Fig. 8).

We observed a similar laboratory pattern of the spectral anisotropy of water using MODIS/ Terra observations obtained over the Passo Real reservoir (south of Brazil). The reservoir was spectrally dominated by variations in TSS, as reported in previous works. ${ }^{3}$ 国 Angular and directional effects on the TSS-bearing waters were highlighted after plotting MODIS surface reflectance data from 13 consecutive dates (Fig. Q). The reservoir was sensed by MODIS at one nadir view and six off-nadir views in each direction (backscattering and forward scattering directions) [Fig. Q(a)]. In agreement with the laboratory observations, results showed more anisotropic waters for VZA greater than $\pm 30 \mathrm{deg}$ from nadir [Fig. 9(b)]. This value represented a threshold to avoid directional and angular effects to estimate TSS using empirical models based on the reflectance of single bands.

In agreement with the results of Fig. 8, when data acquired in VZA larger than \pm 30 deg were used to estimate TSS from single-band models, an overestimation of this constituent was 

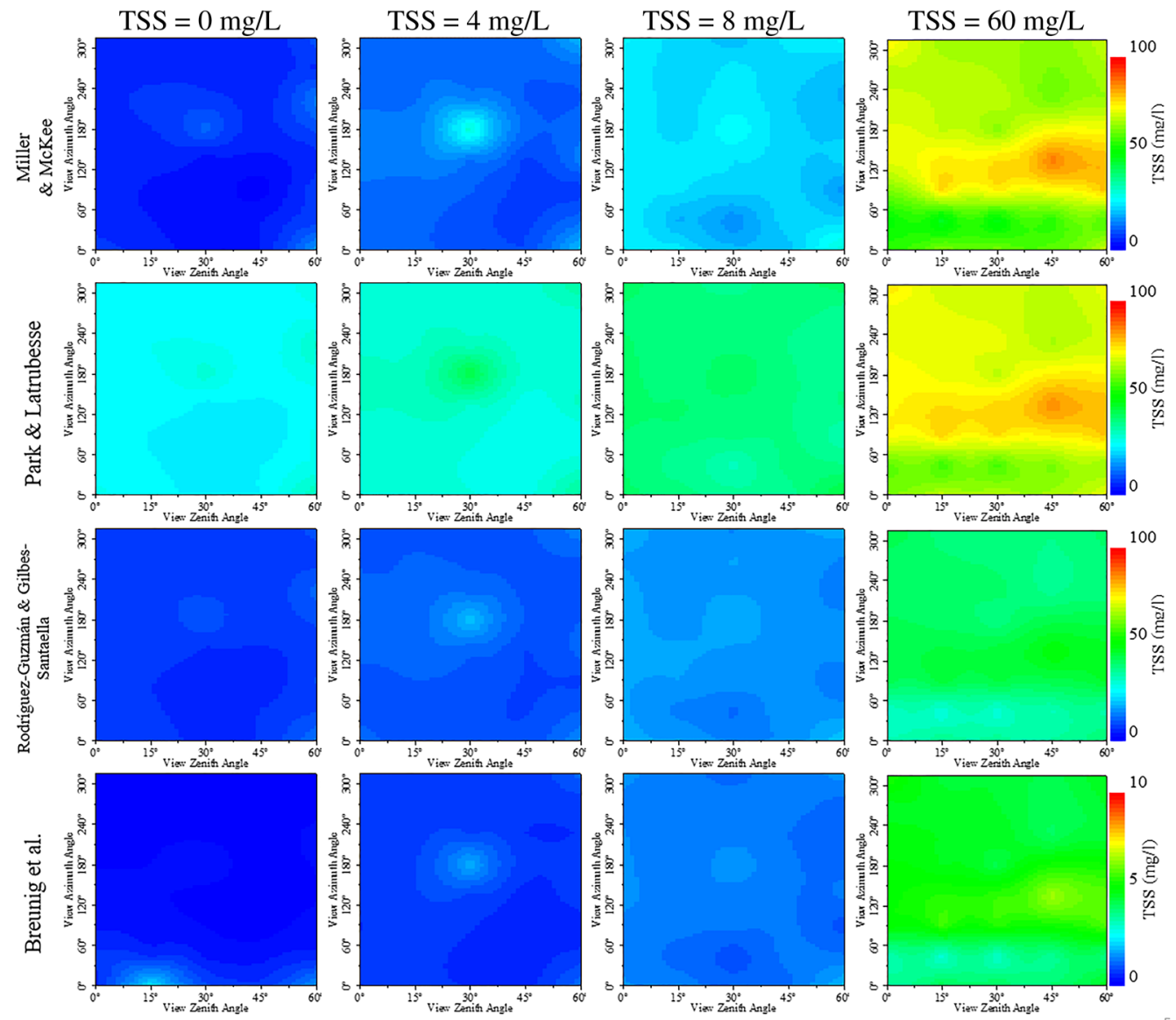

Fig. 8 Directional and angular effects on TSS estimated from four empirical models are shown (rows). For each model, results are illustrated from clear waters to waters with concentrations of 4 , 8.67 , and $60 \mathrm{mg} / \mathrm{L}$ (columns). Results from the specular nearby direction are omitted for better graphic representation. The estimates increase from blue to red colors.

(a)

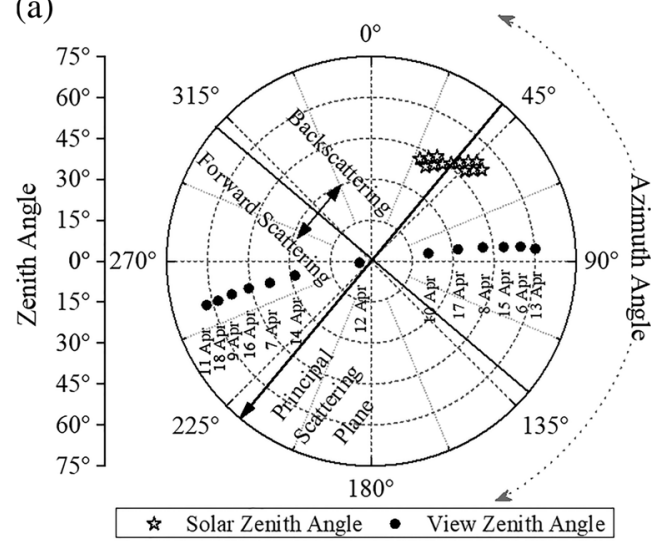

(b)

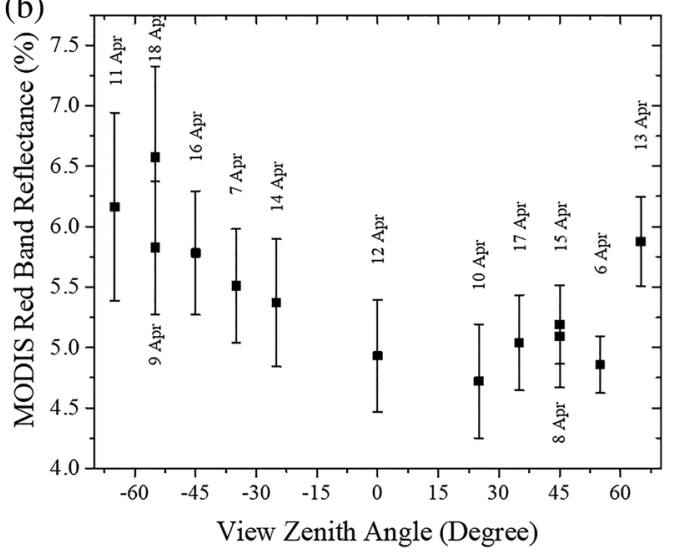

Fig. 9 (a) MODIS geometry of data acquisition during consecutive satellite overpasses in the Passo Real reservoir, South Brazil. (b) Variations in reflectance of the MODIS red band with VZA. Negative sign indicates the forward scattering direction, while positive sign refers to the backscattering direction. 
achieved. By filtering the data up to \pm 30 deg VZA, the directional and angular effects were reduced over the estimates.

\section{Conclusions}

In the laboratory, our findings showed that the spectral reflectance of the waters and their derived TSS estimates were affected by view angle and view direction. SZA had a small variation in our experiment $(5.98 \mathrm{deg})$. A decreasing anisotropy (ANIF) of the water was observed with increasing amounts of TSSs. The best wavelength to estimate TSSs was $625 \mathrm{~nm}$ for most VZAs and VAAs. Considering MODIS-simulated data, the orthogonal plane VAA seemed more adequate for such purpose. The lowest correlations between reflectance and TSS were obtained at extreme viewing in the specular direction (VAA of $180 \mathrm{deg}$ and nearby). When using MODIS-simulated data, TSS underestimates were observed close to the orthogonal plane (90-deg and 270-deg VAA) for all VZAs. In contrast, TSS overestimates were noted in the principal scattering plane in the forward scattering direction.

The pattern of water spectral anisotropy observed in the laboratory was confirmed by original MODIS data acquired over the Passo Real reservoir in Brazil, having high TSS concentrations. In agreement with the laboratory observations, more anisotropic waters were observed for VZA greater than \pm 30 deg from nadir. Close to the orthogonal plane (VAA of $90 \mathrm{deg}$ ), a lesser degree of variation in the spectral shape was observed, except for extreme viewing at 60-deg VZA. The results highlighted the need of further studies to evaluate correction of MODIS data for bidirectional effects when using empirical models based on the reflectance of a single band to estimate TSS. Furthermore, such effects can be likely reduced when using band ratios or composite reflectance products to compensate for significant differences in MODIS viewing geometry during data acquisition.

\section{Acknowledgments}

This research was funded by Brazilian National Council for Scientific and Technological Development (CNPq) (Grant Nos. 113769/2018-0, 309030/2017-0, 310758/2016-5, and 168869/2014-4). We thank the Federal University of Santa Maria (UFSM) and the Brazilian National Institute for Space Research (INPE) for the assistance in the postdoctoral study. We thank the team of students for their valuable assistance during the data collection. Comments by the anonymous reviewers were highly appreciated.

\section{References}

1. D. S. Ahearn et al., "Land use and land cover influence on water quality in the last freeflowing river draining the western Sierra Nevada, California," f. Hydrol.3313(3-4), 234-247 (2005).

2. C. Giardino et al., "Evaluation of multi-resolution satellite sensors for assessing water quality and bottom depth of Lake Garda," Sensors (Basel) 14(12), 24116-24131 (2014).

3. O. C. Montanher et al., "Empirical models for estimating the suspended sediment concentration in Amazonian white water rivers using Landsat 5/TM," Int. J. Appl. Earth Obs. Geoinf. 29(1), 67-77 (2014).

4. A. Morel et al., "Examining the consistency of products derived from various ocean color sensors in open ocean (case 1) waters in the perspective of a multi-sensor approach," Remote Sens. Environ. 111(1), 69-88 (2007).

5. K. Song et al., "Retrieval of total suspended matter (TSM) and chlorophyll-a (Chl-a) concentration from remote-sensing data for drinking water resources," Environ. Monit. Assess. 184(3), 1449-1470 (2012).

6. J. J. Wang and X. X. Lu, "Estimation of suspended sediment concentrations using Terra MODIS: an example from the Lower Yangtze River, China," Sci. Total Environ. 408(5), 1131-1138 (2010). 
7. J. E. Min et al., "Monitoring of suspended sediment variation using Landsat and MODIS in the Saemangeum coastal area of Korea," Mar. Pollut. Bult. 64(2), 382-390 (2012).

8. R. K. Sarangi, S. Nayak, and R. C. Panigraphy, "Monthly variability of chlorophyll and associated physical parameters in the southwest Bay of Bengal water using remote sensing data," Indian J. Mar. Sci. 37(3), 256-266 (2008).

9. K. L. Carder et al., "Illumination and turbidity effects on observing faceted bottom elements with uniform Lambertian albedos," Limnol. Oceanogr. 48(1part2), 355-363 (2003).

10. J. Hedley, "A three-dimensional radiative transfer model for shallow water environments," Opt. Express 16(26), 21887-21902 (2008).

11. C. D. Mobley et al., "Comparison of numerical models for computing underwater light fields," Appl. Opt. 32(36), 7484-7504 (1993).

12. Z. P. Lee et al., "An inherent-optical-property-centered approach to correct the angular effects in water-leaving radiance," Appl. Opt. 50(19), 3155 (2011).

13. S. Hlaing et al., "Assessment of a bidirectional reflectance distribution correction of above-water and satellite water-leaving radiance in coastal waters," Appl. Opt. 51(2), 220 (2012).

14. L. Jun-Sheng et al., "Analysis of directional reflectance proprieties of Lake Taihu using Multi-angle measurements," Spectrosc. Spectr. Anal. 33(9), 2506-2511 (2013).

15. J. T. O. Kirk, Light and Photosynthesis in Aquatic Ecosystems. 2nd ed., Cambridge University Press, Cambridge (1994).

16. G. Schaepman-Strub et al., "Reflectance quantities in optical remote sensing—definitions and case studies," Remote Sens. Environ. 103(1), 27-42 (2006).

17. E. J. Milton et al., "Progress in field spectroscopy," Remote Sens. Environ. 113, S92-S109 (2009).

18. E. J. Milton and E. J. Milton, "Principles of field spectroscopy," Int. J. Remote Sens. 8(12), 1807-1827 (1987).

19. N. K. Singh, S. G. Bajwa, and I. Chaubey, "Removal of surface reflection from above-water visible-near infrared spectroscopic measurements," Appl. Spectrosc. 62(9), 1013-1021 (2008).

20. M. H. Gholizadeh, A. M. Melesse, and L. Reddi, "A comprehensive review on water quality parameters estimation using remote sensing techniques," Sensors (Basel] 16(8), 1298 (2016).

21. K. Shi et al., "Long-term remote monitoring of total suspended matter concentration in Lake Taihu using 250 m MODIS-Aqua data," Remote Sens. Environ. 164, 43-56 (2015).

22. E. M. Latrubesse, J. C. Stevaux, and R. Sinha, "Tropical rivers," Geomorphology 70(3-4 SPEC. ISS.), 187-206 (2005).

23. A. N. Tyler et al., "Remote sensing of the water quality of shallow lakes: A mixture modelling approach to quantifying phytoplankton in water characterized by high-suspended sediment," Int. J. Remote Sens. 27(8), 1521-1537 (2006).

24. P. Curran and E. M. Novo, "The relationship between suspended sediment concentration and remotely sensed spectral radiance: a review," J. Coast. Res. 4(3), 351-368 (1988).

25. M. A. Lodhi et al., "The potential for remote sensing of loess soils suspended in surface waters," J. Am. Water Resour. Assoc. 33(1), 111-117 (1997).

26. A. G. Dekker, R. J. Vos, and S. W. M. Peters, "Analytical algorithms for lake water tsm estimation for retrospective analyses of TM and SPOT sensor data," Int. J. Remote Sens. 23(1), 15-35 (2002).

27. E. Park and E. M. Latrubesse, "Modeling suspended sediment distribution patterns of the Amazon River using MODIS data," Remote Sens. Environ. 147, 232-242 (2014).

28. V. Rodríguez-Guzmán and F. Gilbes-Santaella, "Using MODIS 250 m imagery to estimate total suspended sediment in a tropical open bay," Int. J. Syst. Appl. Eng. Dev. 3(1), 36-44 (2009).

29. D. Doxaran, J.-M. Froidefond, and P. Castaing, "Remote-sensing reflectance of turbid sediment-dominated waters. Reduction of sediment type variations and changing illumination conditions effects by use of reflectance ratios," Appl. Opt. 42(15), 2623 (2007).

30. S. Dutkiewicz et al., "Capturing optically important constituents and properties in a marine biogeochemical and ecosystem model," Biogeosciences 12(14), 4447-4481 (2015). 
31. C. D. Mobley, Light and Water: Radiative Transfer in Natural Waters, Academic Press, Cambridge, Massachusetts (1994).

32. C. D. Mobley, "Estimation of the remote-sensing reflectance from above-surface measurements," Appl. Opt. 38(36), 7442 (1999).

33. A. Morel, D. Antoine, and B. Gentili, "Bidirectional reflectance of oceanic waters: accounting for Raman emission and varying particle scattering phase function," Appl. Opt. 41(30), 6289 (2002).

34. ASD Inc., HandHeld: Hand-Held VNIR Spectroradiometer, ASD, Boulder (2009).

35. Labsphere Inc., Reflectance Reference Targets - Spectralon ${ }^{\circledR}$ Calibrated Diffuse Reflectance Targets, Labsphere, Inc., North Sutton (2009).

36. R. L. Miller and B. A. McKee, "Using MODIS Terra $250 \mathrm{~m}$ imagery to map concentrations of total suspended matter in coastal waters," Remote Sens. Environ. 93(1-2), 259-266 (2004).

37. R. E. Wolfe et al., "Achieving sub-pixel geolocation accuracy in support of MODIS land science," Remote Sens. Environ. 83(1-2), 31-49 (2002).

38. M. L. Campagnolo and E. L. Montano, "Estimation of effective resolution for daily MODIS gridded surface reflectance products," EEEE Trans. Geosci. Remote Sens. 52(9), 5622-5632 (2014).

39. J. Peng et al., "Characterizing the pixel footprint of satellite albedo products derived from MODIS reflectance in the Heihe River Basin, China," Remote Sens. 7(6), 6886-6907 (2015).

40. Z. Han, Y. Q. Jin, and C. X. Yun, "Suspended sediment concentrations in the Yangtze River estuary retrieved from the CMODIS data," Int. J. Remote Sens. 27(19), 4329-4336 (2006).

41. J. Ritchie, F. Schiebe, and J. McHenry, "Remote sensing of suspended sediments in surface waters," Am. Soc. 42, 1539-1545 (1976).

42. L. Wang et al., "Retrieval of total suspended matter from MODIS $250 \mathrm{~m}$ imagery in the Bohai Sea of China," J. Oceanogr. 68(5), 719-725 (2012).

43. F. M. Breunig et al., "Assessing the long-term variability of TSS and chlorophyll in subtropical reservoirs using MODIS data," IEEE J. Sel. Top. Appl. Earth Obs. Remote Sens. 9(12), 5406-5412 (2016).

44. M. A. Friedl et al., "Characterization of North American land cover from NOAA-AVHRR data using the EOS MODIS land cover classification algorithm," Geophys. Res. Lett. 27(7), 977-980 (2000).

45. W. Lucht and P. Lewis, "Theoretical noise sensitivity of BRDF and albedo retrieval from the EOS-MODIS and MISR sensors with respect to angular sampling," Int. J. Remote Sens. 21(1), 81-98 (2000).

46. W. Lucht, "Expected retrieval accuracies of bidirectional reflectance and albedo from EOSMODIS and MISR angular sampling," T. Geophys. Res. 103(D8), 8763-8778 (1998).

47. W. Lucht, C. B. Schaaf, and A. H. Strahler, "An algorithm for the retrieval of albedo from space using semiempirical BRDF models," IEEE Trans. Geosci. Remote Sens. 38(2), 977-998 (2000).

48. J. Dwyer and G. Schmidt, "The MODIS reprojection tool," in Earth Science Satellite Remote Sensing, V. V. Qu et al., Eds., Springer Berlin Heidelberg, Berlin Heidelberg, pp. 162-177 (2006).

49. E. M. Novo, J. D. Hansom, and P. J. Curran, "The effect of sediment type on the relationship between reflectance and suspended sediment concentration," Int. J. Remote Sens. 10(7), 1283-1289 (1989).

50. F. M. Breunig et al., "Dynamics of limnological parameters in reservoirs: a case study in South Brazil using remote sensing and meteorological data," Sci. Total Environ. 574, 253-263 (2017).

Fábio M. Breunig is an associate professor at the Federal University of Santa Maria (Brazil) campus of Frederico Westphalen, RS, Brazil. He is a geographer with MS and PhD degrees in remote sensing from the Brazilian National Institute for Space Research (INPE). Currently, he is working with applications of remote sensing, focusing on directional effects, radiative transfers modeling, and multiscale data integration (ground, UAV, and orbital data). He is a member of Selper International. 
Waterloo Pereira Filho received his geographer degree from the Federal University of Santa Maria, Santa Maria, Brazil; his MS degree in remote sensing from Brazilian National Institute for Space Research (INPE), Sao Jose dos Campos, Brazil; and his PhD in geography from the University of São Paulo (USP), São Paulo, Brazil. Since 1990, he has been a professor at the Federal University of Santa Maria. His research interests include the remote sensing of inland waters and environments.

Lênio S. Galvão is a researcher at the INPE in Brazil. He is a geologist with an MS degree in remote sensing from INPE and a PhD in geophysics from USP. His research interest includes reflectance spectroscopy and hyperspectral remote sensing. He has performed several investigations using airborne (e.g., AVIRIS, HYMAP) and orbital (e.g., Hyperion/EO-1 and CHRIS/ PROBA) imaging spectrometers.

Biographies of the other authors are not available. 